\title{
Malestares de género: identidad e inclusión democrática
}

\author{
Fernando FERNÁNDEZ-LLEBREZ
}

Recibido: 12 de abril de 2011.

Aceptado: 18 de agosto de 2011 .

\section{RESUMEN}

El propósito de este artículo es realizar una aproximación crítica al concepto de identidad de género y sexual desde la teoría política democrática. Tras una crítica a las "políticas de identidad" de carácter culturalista, se defenderá la dimensión política, fluida y dinámica de las identidades. Para ello se hará un recorrido por las distintas concepciones sobre la identidad de género y sexual hasta llegar al planteamiento llevado a cabo por los y las transgenéricas. Finalmente, se señalará la necesidad de defender las identidades de género y sexuales como un continuum, siendo esta la que mejor nos capacita para llevar a cabo la inclusión, la igualdad y la libertad democrática en nuestras sociedades.

\section{PALABRAS CLAVE}

Género, identidad, democracia, teoría política, feminismos.

\begin{abstract}
The objective of this article is to offer a critical examination of the concept of gender and sexual identity from the perspective of democratic political theory. After a critique of culturalist identity politics, this article makes a defense of the political, fluid and dynamic dimensions of identities. For this purpose we examine the various approaches to gender and sexual identity, particularly the transgender perspective. In conclusion, a vision of gender and sexual identities as a continuum is most in accord with the possibility of providing democratic inclusion, equality and liberty in our societies.
\end{abstract}

\section{KEYWORDS}

Gender, identity, democracy, political theory, feminisms. 
Un deseo salvaje ha fluido de mi corazón a mi cabeza y no lo reprimiré aunque pueda excitar carcajadas. Deseo honestamente ver cómo la distinción de los sexos se confunde en la sociedad.

Mary Wollstonecraft ${ }^{1}$.

\section{Democracia, POLÍticas de IDENTIDAd Y GÉNERo}

Forma parte del legado de la teoría democrática moderna la cuestión de la inclusión del otro como ejercicio del pluralismo democrático ${ }^{2}$. Un legado que no quita para reconocer que no siempre ocurre así en la práctica democrática. Por eso, es una constante la discusión sobre el reconocimiento de derechos colectivos que tienen que ser tenidos en cuenta para garantizar la igualdad. Ejemplos de estas polémicas son las políticas de igualación socio-económica que, a lo largo del siglo veinte, se han ido desarrollando en las democracias occidentales, así como las demandas del movimiento sufragista feminista en favor de la obtención de derechos políticos para las mujeres ${ }^{3}$. Políticas que a través de la ampliación de derechos ciudadanos de carácter general suponían la inclusión jurídica de ciertos grupos e intereses.

En fechas más recientes, y dentro de este marco democrático, también ha sido habitual vincular la política del reconocimiento con ciertos derechos de grupos $^{4}$. Entre los que hoy se consideran como derechos de reconocimiento se encuentran cuestiones como la desigualdad entre los géneros y las opciones sexuales, los conflictos étnicos, nacionales, etc. Pese a sus diferencias, que las hay y no son baladíes, todas ellas remiten, o dicen remitir, a aspectos relacionados con la identidad social y personal de dichos grupos. Por eso es común definir tales politicas de reconocimiento como políticas de identidad que actúan sobre problemáticas específicas.

No obstante, es preciso señalar que realmente la distinción entre derechos generales (ampliación del voto) y derechos específicos (cuota de representación) p. 185.

${ }^{1}$ Mary Wollstonecraft, Vindicación de los Derechos de la Mujer, Cátedra, Madrid, 1994,

${ }^{2}$ Seyla BenhabiB, El Ser y el Otro en la ética contemporánea, Gedisa, Barcelona, 2006.

${ }^{3}$ Cristina SÁnchez, "Genealogía de la vindicación", en Elena Beltrán y Virginia MaquieIRA (eds.), Feminismos. Debates teóricos contemporáneos, Alianza, Madrid, 2001, pp. 17ss.

${ }^{4}$ Para una reciente aproximación a esta cuestión véase Ferrán ReQuejo, "El fuste de la democracia liberal sigue siendo demasiado recto": Foro Interno. Anuario de Teoría Política, vol. 10 (2010), pp. 51-70. 
es algo definido a posteriori puesto que, en un principio, todos los avances remitían a sujetos concretos, como, por ejemplo, el voto para las mujeres o los negros; lo que nos indica cierta relación entre los derechos de redistribución y de reconocimiento. Como acertadamente señala Nancy Fraser, desde el punto de vista analítico, el reconocimiento y la redistribución remiten a problemáticas distintas, de tal modo que lo que se consigue en uno de ellos no se traslada, necesariamente, al otro. Pero que esto sea así no significa que no haya conexión entre ambos y más en ciertas cuestiones como las relativas al género, donde podemos hablar de comunidades bivalentes ${ }^{5}$ al verse afectadas por ambas lógicas.

En nuestro caso, no vamos a hablar de todas las politicas de identidad, sino de aquellas que afectan al binomio género/sexo. Problemática que, como otras, requiere una atención especial por lo que conlleva en sí misma y por sus repercusiones para el conjunto de la teoría democrática.

Las políticas de identidad tienen su justificación a partir del reconocimiento de que hay relaciones de desigualdad, exclusión, marginación o negación que deben ser reformuladas en aras de una mayor o plena igualdad. Como recuerda Iris Marion Young, sin esas relaciones asimétricas las políticas de identidad no tienen sentido político ni social, de ahí que queden vinculadas a alguna forma de definir la injusticia, la opresión, o conceptos de índole similar, que rompen la teórica neutralidad ${ }^{6}$; una fractura que desvela la existencia de sujetos concretos y encarnados, entre los que emergen, por ejemplo, el varón de mediana edad, de clase media, blanco e instruido.

Ante esa realidad discriminatoria la defensa de las politicas de identidad conlleva una serie de medidas que intentan paliar, o erradicar, dicha situación. Ejemplos de esto lo tenemos en las políticas de discriminación o afirmación positiva, en la exigencia de igualdad ante la ley, en las políticas de paridad y de atención sanitaria (SIDA), en la defensa del orgullo gay y del día de la mujer, etc. Como dice Diana Fuss en relación a la cuestión gay — aunque sería válido para otras problemáticas-: "las políticas de identidad se han utilizado por parte de activistas gays como algo parecido a un grito de recomposición para estimular la conciencia personal y la acción política"7, actuando, tales políticas, como "polí-

\footnotetext{
${ }^{5}$ Nancy Fraser, “¿De la redistribución al reconocimiento? Dilemas de la justicia en la era postsocialista": New Left Review, n. ${ }^{\circ}$ 0, Akal, Madrid, 2000, pp. 129ss.

${ }^{6}$ Iris M. YounG, "Vida política y diferencia de grupo: una crítica del ideal de ciudadanía universal", en Carme CAstells (comp.), Perspectivas feministas en teoría política, Paidós, Barcelona, 1996, p. 111.

${ }^{7}$ Diana Fuss, Teoría gay y lesbiana: el tema de las políticas de identidad, copia mimeografiada, 1990, p. 1.
} 
ticas de afirmación"8. Estas exigencias son realidades (y deseos) que fueron y siguen siendo necesarias para plantear la indeseable desigualdad existente hoy en día. En este sentido, consideramos que tales medidas son herramientas sociales y políticas todavía hoy legítimas ante las situaciones de exclusión e injusticia reinante, pese a que no son la única, ni a veces la mejor, forma de abordar dichas injusticias.

En cualquier caso, no todas las políticas de identidad son defendidas de la misma manera. Como parece obvio, en todas estas políticas, la propia cuestión de qué es la identidad ocupa un lugar significativo. Pero a partir de esta idea general se han elaborado diferentes formas de acercarse a ellas. Diferencias que vienen marcadas por el tipo de relación que se dé entre política e identidad.

Por un lado, están aquellas teorías sobre la identidad que podríamos denominar como culturalistas que tienen como fundamento teórico "levantar una comunidad política cohesionada y visible" en donde la conceptualización sobre qué es la identidad, y el lugar que ocupa en nuestra vidas, se convierte en el elemento causal que define el tipo de políticas de las que estamos hablando.

Esta concepción culturalista afecta a una pluralidad de pensadores y pensadoras. En el terreno feminista, la corriente denominada como feminismo cultu$\mathrm{ral}^{10}$ es la que, de forma paradigmática, mejor la representa. Pero también hay otras teóricas - dispares entre sí y alejadas de dicha corriente-, como Luce Irigaray, Barbara Smith o Audre Lorde ${ }^{11}$, entre otras, que compartirán la idea de que tenemos una política porque anteriormente tenemos una identidad. La propia Smith lo señala de forma contundente en el siguiente párrafo:

[C]omo mujeres negras tenemos una identidad y, por lo tanto, una política que exige fe en la humanidad negra. Nos estamos oponiendo abiertamente a las con-

${ }^{8}$ Jeffrey WeEks, El malestar de la sexualidad. Significados, mitos y sexualidades modernas, Talasa, Madrid, 1993, p. 294.

${ }^{9}$ Fuss, Teoría gay y lesbiana, p. 1.

${ }^{10}$ A este menester, puede verse, entre otras autoras: Andrea Dworkin, Right-Wing Women, Perigee Books, New York, 1983, passim; y Mary Daly, Gyn/Ecology, Beacon Press, Boston, 1978, passim. Para un excelente recorrido por el feminismo cultural: Raquel OsBORNE, La construcción sexual de la realidad, Cátedra, Madrid, 1993, passim.

${ }^{11}$ Luce IrIgaraY, Yo, tú, nosotras, Cátedra, Madrid, 1992, passim.; Gloria T. Hull, Patricia B. Scotт, Barbara Sмith (eds.), All the Women Are White, All the Blacks Are Men, But Some of Us Are Brave: Black Women's Studies, Feminist Press, Old Westbury, New York, 1982, passim; y Audre LORDE, La hermana, la extranjera: artículos y conferencias, Horas y Horas, Madrid, 2003, passim. 
cepciones de los hombres blancos de lo que es la humanidad y demostrando que no es una cuestión de ellos, sino de nosotras ${ }^{12}$.

De este modo, la política adecuada es la consecuencia de una identidad que está previamente establecida y claramente asentada y definida. Es como si la identidad fuera algo que siempre ha estado allí y que lo único que nos queda es reconocerla tal y como se manifiesta, tal y como se expresa.

Por otro lado, se encuentran quienes, como Amy Gutmann, plantean justamente la cuestión de forma inversa. Para Gutmann, desde el punto de vista democrático, una política de identidad tiene su justificación en lo que públicamente trata de conseguir y expresar, y no en la existencia de una identidad predefini$\mathrm{da}^{13}$, por lo que la causalidad está en su dimensión política y no en la propia identidad. Un planteamiento que, en contraposición con el anterior, lo podríamos denominar como político o cívico.

Tirando de este hilo teórico, en el que se sitúan autoras feministas como la citada Gutmann, la arendtiana Seyla Benhabib, la pragmática Nancy Fraser e, incluso, la humanista Martha Nussbaum — cada una distinta de la otra, pero relacionadas entre sí-, pretendemos discutir la perspectiva culturalista con la intención de saber si es la mejor forma de definir la identidad, y en concreto las referidas a los géneros y los sexos, y en qué medida este planteamiento esencializa la propia idea de identidad confundiendo conceptos como esencia e identidad. Si esto fuera así, entonces, se tornaría preciso reescribir y "reteorizar" el propio concepto de identidad, así como la relación que se establece entre democracia moderna e identidad, pudiéndose hablar, cuanto menos, de una relación bidireccional entre ambos conceptos.

Esta problematización de la identidad tiene como propósito buscar una mejor y más adecuada conceptualización de los procesos identitarios de género y de sexualidad en nuestras democracias. Pero no lo hace tratando de crear el modelo definitivo y auténtico de género como si este fuera la nueva síntesis dialéctica que pretende encontrar la solución final a todos los problemas ${ }^{14}$. Tal planteamiento choca con una perspectiva política y democrática de la identidad, como la nuestra, la cual está sujeta a las imperfecciones y contradicciones que la propia democracia contiene. Si la democracia es un planteamiento que se lleva

${ }^{12}$ Citado por Fuss, Teoría gay y lesbiana, p. 3.

13 Amy Gutmann, La identidad en democracia, Katz, Madrid, 2008, p. 271.

${ }_{14}$ Javier Roiz, La recuperación del buen juicio. Teoría política en el siglo veinte, Editorial Foro Interno, Madrid, 2003, pp. 13-64. 
mal con la omnipotencia ${ }^{15}$, entonces, las identidades de género y sexo que se den en su seno no podrán ser perfectas ni totales, sino que se caracterizarán por ser dinámicas, complejas y fluidas. Y si queremos que dichas identidades emerjan y florezcan es preciso - es condición sine qua non- dotarse de un planteamiento teórico sobre dichas identidades que abra el campo de las posibilidades democráticas para que sea factible vivir de forma inclusiva nuestra vida con géneros. Es cierto que esta concepción de las identidades queda vinculada a las exigencias normativas de las democracias modernas (libertad, igualdad, inclusión, pluralismo...), excluyendo ciertos comportamientos que quedan fuera de dichas exigen$\operatorname{cias}^{16}$. Pero también lo es que no tiene un afán normativizador ni vigilante en el sentido de definir, y perseguir, una única forma de ser hombre, mujer; pues se concibe como un lugar para el reconocimiento y la redistribucción identitaria en el que cabrán una variedad de formas de sentirnos, más allá de que a alguien le satisfaga más una que otra.

En definitiva, se trata de configurar una concepción de la identidad que, inspirada en criterios humanistas ${ }^{17}$, sea menos excluyente $y$, a la vez, esté alejada del dogmatismo y, por tanto, tenga mayor capacidad para abordar la pluralidad y complejidad de nuestra vida con géneros en las sociedades democráticas avanzadas.

Para ello, tomaremos como punto de inflexión realidades identitarias ya existentes que, por ser consideradas como "no normales", han sido y son estigmatizadas, pero que son, sin embargo, tan reales como la vida misma y con la misma legitimidad que las comúnmente reconocidas. Nos referimos a las posibilidades que abren los y las transexuales (y los drag queen) ${ }^{18}$ tanto para ellos y ellas mismas como para el conjunto de las "personas con género" (sea este el que sea). Todo un reto para el siglo veintiuno.

${ }^{15}$ Fernando Fernández-LLEBrez, "Pensamiento trágico y ciudadanía compleja: crítica a la razón omnipotente": Foro Interno. Anuario de Teoría Política, vol. 1 (2001), pp. 46ss.

${ }^{16}$ Por ejemplo, y entre otros, aquellos que supongan la negación del otro.

${ }^{17} \mathrm{El}$ vocablo humanista es polivalente. En nuestro caso remite al humanismo retórico de origen grecolatino. Entre sus autores clásicos podemos destacar, entre otros, a Marco Fabio Quintiliano (circa 39- circa 95), Nicolás Maquiavelo (1469-1527) y Giambattista Vico (1668-1744). Y más recientemente a Hannah Arendt (1906-1975), Quentin Skinner, Javier Roiz, Sheldon S. Wolin y la sefardí Seyla Benhabib. Para un recorrido por dicha tradición, véase Víctor Alonso, Retórica, democracia y crisis. Un estudio de teoría política, Centro de Estudios Constitucionales, Madrid, 2010, passim. Sin formar parte de esta tradición, pero con un humanismo de influencias senequistas y ciceronianas, véase Martha NussBaum, El cultivo de la humanidad. Una defensa clásica de la reforma de la educación liberal, Paidós, Barcelona, 2005, passim.

${ }^{18}$ Judith ButLer, Gender Trouble: Feminism and the Subversion of Identity, Routledge, New York, 1999, pp. 10ss. y 174ss. 
Y, por último, nos aproximaremos a dicha reflexión desde un pensamiento feminista ${ }^{19}$ que se tomará en serio una de las afirmaciones feministas más característica como fue la realizada por Simone de Beauvoir (1908-1986) en relación a que la mujer no nace, sino que se hace ${ }^{20}$, y que puede y debe ser extensible también a los hombres.

\section{IDENTIDADES INDIVIDUALES Y COLECTIVAS}

Por lo menos desde la modernidad en adelante, y sobre todo desde mediados del siglo diecinueve, las identidades, ya sean individuales y/o colectivas, se caracterizan por una serie de rasgos. De los variados factores que las definen destacaremos los dos siguientes.

Por un lado, su carácter complejo ${ }^{21}$. La identidad tiende a "identificar" a los iguales dentro de un mismo grupo, e incluso a una persona, en relación a otros grupos o personas, dando sentido propio y posibilitando la afirmación y autoafirmación. De este modo, podemos decir que la identidad une, como queda reflejado en aspectos tales como ser mujer, orgullo gay, etc.

Al mismo tiempo, la identidad sirve también para diferenciar a unos y unas de otros y otras. Marca distancia entre los no iguales y abre un espacio entre los que se ubican en un lugar y los que no lo están. En este sentido, la identidad marca distancias y diferencias entre los iguales y los no iguales. En algunos casos, muchos por desgracia, esa diferenciación es una clara negación del otro, lo que acarrea problemas nada baladíes.

Así, la identidad se mueve en un terreno complejo, contradictorio que, a la vez, une y diferencia ${ }^{22}$. Seguramente sea en este factor en donde resida tanto su limitación como su fuerza. Una dualidad que se ha desarrollado, la más de las veces, de la siguiente manera: a mayor identificación y afirmación interna, mayor es la diferenciación y no reconocimiento del otro. Cuanto más se tira de un hilo, más lejos queda el contrario. A mayor diferenciación y afirmación propia (del adentro), mayor desconsideración del otro (del afuera).

${ }^{19}$ Es necesario recordar que no existe un único feminismo, siendo obligado hablar de este en plural: feminismos. De hecho, en nuestro caso tomaremos aportaciones de más de uno, aunque alguno tendrá más peso que otros.

${ }^{20}$ Simone de Beauvorr, El segundo sexo, Cátedra, Madrid, 1999, passim.

${ }^{21}$ Edgar MoRIn, Introducción al pensamiento complejo, Gedisa, Barcelona, 1994, passim.

${ }^{22}$ Una mirada retórica, y crítica, sobre la "lógica de la identidad" en Ricardo CARRILlo y Jacobo SAIBACAM, "El mundo interno, el imaginario y la política": Foro Interno. Anuario de Teoría Política, vol. 10 (2010), pp. 97-102. 
Como nos ha recordado Jeffrey Weeks, si miramos la historia de los "grupos de afirmación sexual" apreciamos como estos han ido feneciendo en función de cómo han actuado ante dicha situación. Si se tira excesivamente de un lado, la negación del otro suele conllevar cierto tipo de "guetificación" que supone su práctica desaparición. Por el contrario, cuando se diluye en exceso su personalidad suele producirse su desaparición por el camino inverso, es decir, por ser "asimilados". Ambas realidades y tensiones forman parte, aunque no solo, de los distintos grupos que llevan a cabo exigencias sobre políticas de identidad ${ }^{23}$.

Por otro lado, es una constante que se establezca algún tipo de relación entre las identidades individuales y colectivas. La vinculación entre estas identidades es, de hecho, variada y múltiple, habiéndolas más fuertes y más débiles, aunque siempre se dé algún tipo de relación entre ellas.

Las experiencias organizativas sociales y políticas más significativas dentro de la problemática de género y sexo, es decir, las que mayor fuerza social e impacto ambiental tienen y han tenido, se han caracterizado, en la mayoría de los casos, por establecer un tipo de relación fuerte entre las identidades individuales y colectivas ${ }^{24}$. Es cierto que, unas veces, esta fuerte relación ha sido solo al principio de la experiencia y que, en otros casos, esta ha perdurado durante mucho más tiempo (incluso hasta el "final de sus días"). Pero sea de la forma que sea, en términos mayoritarios, esta relación ha sido de carácter fuerte. Una fuerte vinculación que ha estado, y está, relacionada con cuatro aspectos. En primer lugar, con el cuestionamiento de la relación existente entre lo público y lo privado en nuestras sociedades. Este elemento es uno de los ejes característicos del poderío de todos estos grupos y movimientos. La famosa consideración de que lo personal es político está por detrás de estos planteamientos, sobre todo a partir de los años sesenta.

Hay muchas formas de abordar la idea de lo personal es político. De manera general, supone un cuestionamiento de la dicotomía clásica público versus privado, aunque este es plural. Hay quienes cuestionan esta dicotomía con la intención de negar la diferenciación entre lo público y lo privado (que tendría como consecuencia una relación fuerte entre lo individual y lo colectivo). Pero también hay quienes lo que pretenden hacer es, más bien, una redefinición, más o menos

${ }^{23}$ WeEKs, El malestar de la sexualidad, pp. 293-334.

${ }^{24}$ Para un recorrido feminista crítico por esta y otras problemáticas, véase Paloma URÍA, $E l$ feminismo que no llegó al poder. Trayectoria de un feminismo crítico, Talasa, Madrid, 2009, passim. 
profunda de la misma (y su consecuencia es la de una relación débil entre lo individual y lo colectivo $)^{25}$.

En segundo lugar, con la necesidad de dar reconocimiento social y político a una opresión o injusticia, la cual requiere de una entrada en la arena pública que sea nítida y contundente. Una forma habitual de reafirmar este hecho es reforzar y simplificar (por múltiples vías) la identidad colectiva del grupo correspondiente, lo que genera mayor seguridad y firmeza a los planteamientos propios.

En tercer lugar, con la afirmación de una identidad de la que hay que sentirse orgulloso y orgullosa. Significa la dignificación de una parte de las vidas de ciertas personas que han sido negadas, lo que conlleva la afirmación de algo de lo que hay que vanagloriarse, para que así se puedan mirar a la cara (y a las caras) y no tener que bajar la cabeza.

$\mathrm{Y}$, en cuarto lugar, con el hecho de que las identidades individuales y colectivas de carácter fuerte suelen ir acompañadas de un elemento que termina definiendo al conjunto de la identidad colectiva: la proyección de una identidad individual (ser gay, lesbiana, transexual, transgenérica, etc.) como la representante genuina de la identidad colectiva, de tal modo que la identidad colectiva se define a partir de la correspondiente identidad individual. Esta proyección viene cargada por dos rasgos muy significativos. Por un lado, supone cosificar la identidad individual, definiendo una identidad de género y de sexo como la "verdadera" identidad (esencialismo); y por otro, conlleva que esta identidad individual actúe como modelo para el conjunto del grupo, transmutándose la parte hacia el todo y uniformizándose, también, la propia identidad colectiva. El traspaso de una identidad individual a otra colectiva se suele justificar, precisamente, porque se piensa que la identidad solo une a los iguales y no a los diferentes, estampándose las identidades colectivas sobre las individuales como si fueran sellos sobre papel en blanco, quedando calificadas las denominadas "anomalías" como opciones "meramente personales", desgajándolas así de todo su carácter social.

Tras lo dicho cabe preguntarse si lo indicado hasta el momento es cambiable o no. Es decir, ¿ha sido siempre así?, ¿lo es siempre?, ¿tiene que serlo? A este respecto, hay facetas que han sido así históricamente - mostrando, además,

${ }^{25}$ Este sería el caso de la retórica humanista que no remite a un ágora totalizante, sino a la existencia de espacios públicos internos como realidades fundantes de lo público; una idea de lo público sustentada en la libertad. Véase Fernando FernÁNDEZ-Llebrez, "El humanismo cívico como vector de la calidad democrática", en Juan MontaBES y Raquel OJEDA (coords.), Estudios de Ciencia Politica y de la Administración, Tirant Lo Blanch, Valencia, 2009, p. 415. 
aspectos bastantes positivos (aunque también contengan sinsabores amargos)-, pero hay otras que no.

Que las identidades de género y de sexo son realidades complejas es una constante teórica e histórica que forma parte de los estudios y las prácticas sobre las identidades desde hace ya mucho tiempo, por lo menos dentro del mundo moderno. Es cierto que casi todo en la vida puede cambiar, pero no parece que haya indicios para ello en este terreno. Igual pasa con el hecho de que, de alguna manera, hay relación entre las identidades individuales y las colectivas, mostrándose así su historicidad y contingencia.

Sin embargo, no está escrito que tenga que haber desigualdad ni discriminación hacia las mujeres, ni por opciones sexuales u otras. Y no solo esto es evidente, de lo que son un ejemplo las conquistas sociales, políticas y culturales realizadas por las mujeres en este terreno, o las que todavía quedan por alcanzar, sino que no hay democracia digna de tal nombre que no cuestione dicha situación de injusticia. Como tampoco está escrito la manera de concretar el carácter complejo de las identidades de género y de sexo, el cual depende de otros factores como, por ejemplo, la forma en que la identidad se articule públicamente; aspecto este que es variable tanto espacial como temporalmente ${ }^{26}$.

Tampoco está escrita la relación que se establece en cuanto al género y al sexo entre lo individual y lo colectivo, la cual no tiene por qué ser siempre de carácter fuerte, ni conllevar una proyección determinista de lo individual hacia lo colectivo. Lo que sí parece ser común es que, en sus inicios, se dé una intensidad considerable entre lo individual y lo colectivo difícil de eludir (que tiene sus luces y sus sombras). Aún así, el carácter abierto de la relación nos muestra la posibilidad de replantear la dimensión fuerte de la misma. Un replanteamiento que tiene consecuencias no solo sobre la relación entre identidades, sino también sobre la forma de definir la propia identidad, afectándole cuanto menos en dos aspectos: en el carácter natural o construido de la identidad y en la vinculación entre diferencia e igualdad a la hora de su conceptualización.

${ }^{26}$ Para el concepto de articulación véase Chantal Mouffe, La paradoja democrática, Gedisa, Barcelona, 2003, pp. 95ss. Para una aproximación a las identidades colectivas y su relación crítica con el enfoque de Chantal Mouffe, véase Marcos Engelken-Jorge, "Pasiones, identidades colectivas y deliberación: los retos planteados por la democracia agonística": Foro Interno. Anuario de Teoría Política, vol. 10 (2010), pp. 80ss. 


\section{LA TEORÍA DE LOS DOS SEXOS Y LA FALSA INCONMENSURABILIDAD}

Que la forma de definir la identidad varía con el tiempo es algo que se puede apreciar, precisamente, cuando hablamos de la identidad de género. Es sabido que el género es algo cultural que ha ido cambiando a lo largo del tiempo y del espacio. Tal consideración está hoy comúnmente aceptada. Pero resulta que algo parecido ocurre si hablamos del sexo porque la sexualidad, así como la identidad sexual, son cuestiones que también han cambiado a lo largo de la historia ${ }^{27}$. Esta cuestión ya no está tan asumida, siendo uno de los debates de mayor resonancia dentro de la teoría feminista contemporánea.

Si miramos la historia, nos encontramos con dos teorías a la hora de definir el sexo. Por un lado, está la teoría clásica sobre el sexo que, sin dejar de ser usada años más tarde, llega como teoría dominante de carácter explicativo hasta el siglo diecisiete y principios del dieciocho. Esta teoría, defendida por ejemplo por Galeno (130-200 e. c.), es conocida como la de "sexo único" e interpreta a los "cuerpos masculinos y femeninos de forma jerárquica, verticalmente, pero como versiones ordenadas dentro de un solo sexo" 28 .

Por otro lado, está la teoría moderna de los "dos sexos inconmensurables" que vino a sustituir a esta y que se desarrolla a lo largo del siglo dieciocho, que tiene su apogeo en el diecinueve y llega hasta nuestros días. De ahí que tenga razón Thomas Laqueur cuando afirma que "el sexo tal y como lo conocemos [hoy] fue inventado en el siglo XVIII"29. Entonces fue cuando los órganos de reproducción pasaron a ser lugares paradigmáticos que manifestaban la jerarquía, actuando como el fundamento de la diferencia inconmensurable ${ }^{30}$. Así, estructuras que se habían considerado comunes a los hombres y las mujeres, como el esqueleto y el sistema nervioso, fueron diferenciadas para que se correspondieran con el "verdadero hombre" y la "verdadera mujer". El cuerpo, en particular

${ }^{27}$ La obra clásica a la que se remite cuando se habla de esta cuestión es Michel FouCAULT, Historia de la sexualidad, Siglo XXI, Madrid, 1992, passim. Pero no es necesario seguir los postulados foucaultianos para aceptar el carácter constructivo de la sexualidad. Para un ejemplo de ello véase Nussbaum, El cultivo de la humanidad, pp. 235-274, Para un recorrido por la historia de la sexualidad, y en concreto de la homosexual, en el mundo griego: Keneth Dover, Greek Homosexuality, Harvard University Press, Cambridge, Mass, 1986, passim; y para una mirada que llega hasta el siglo pasado: Thomas LAQUEUR, La construcción del sexo. Cuerpo y género desde los griegos hasta Freud, Cátedra, Madrid, 1994, passim.

${ }^{28}$ LAQUeUR, La construcción del sexo, p. 31

${ }^{29}$ Ibidem.

${ }^{30}$ Ibid., pp. 258-259. 
el de la mujer, se convirtió en la regla de oro del discurso social, con todo lo que a él iba vinculado.

Rasgos supuestamente "naturales" como el pretendido desapasionamiento de las mujeres, la carga de la naturaleza y de los procesos cíclicos, los órganos reproductores (que incluso se cambiaron: la matriz, antes vista como una especie de falo negativo, pasó a ser el útero, etc.) se convirtieron en la seña de identidad, nunca mejor dicho, de toda una nueva teoría sobre el sexo y el género. De esta manera, se puede decir que las ideas de las "mujeres como poco afectadas por la sensualidad, como una especie de ángeles, como una 'raza' más pura...destinada a inspirar en el resto de la condición humana sentimientos nobles, generosos y de fidelidad"31, fueron una creación cultural de los hombres y las mujeres de las clases medias de la época; no quedándose solo en su época, sino extendiéndose hasta la actualidad.

Esta concepción del sexo requiere una nueva epistemología para la cual las categorías hombre y mujer son sustancias naturales diferentes que definen "dos sexos biológicos opuestos e inconmensurables" ${ }^{32}$ y que se reconocen dentro de un marco binario y dicotómico. Epistemología esta que no solo se deja ver en el ámbito privado, sino que se traslada al ámbito público a través del concepto de contrato social ${ }^{33}$.

Así, la idea de que hay "dos sexos inconmensurables" era, y es, un producto cultural en la misma medida que lo era, y lo es, la de que hay un "sexo único" ${ }^{34}$. En palabras de Laqueur: "casi todas las afirmaciones relativas al sexo están cargadas desde el principio por la repercusión cultural de las mismas propuestas" ${ }^{35}$. Por ello, es oportuno decir que no solo la identidad es algo construido, sino que las identidades referidas al género y al sexo también lo son ${ }^{36}$. Reconocer esta contingencia no significa negar que las diferencias y las semejanzas,

${ }^{31}$ Ibid., p. 332. Para esta cuestión, véase también: Leonore DAvidoff y Catherine HALL, Fortunas familiares. Hombres y mujeres de la clase media inglesa (1780-1850), Cátedra, Madrid, 1994, passim.

${ }^{32}$ Ibid., p. 226

${ }^{33}$ Ya es clásica la crítica de Mary Wollstonecraft al planteamiento de Jean-Jacques Rousseau (Wollstonecraft, Vindicación de los Derechos de la Mujer, pp. 215ss.). Para una crítica reciente al contractualismo desde un punto de vista humanista y feminista: Martha NuSSBAUM, Las fronteras de la justicia. Consideraciones sobre la exclusión, Paidós, Barcelona, 2006, passim.

${ }^{34}$ LAQUeUR, La construcción del sexo, p. 264.

${ }^{35}$ Ibid., p. 37

${ }^{36}$ Nussbaum, El cultivo de la humanidad, pp. 240-274. 
más o menos recónditas, estén por todas partes, pero sí que cuáles de ellas se tienen en cuenta, y con qué objetivo, es algo que se define fuera de la estricta investigación empírica ${ }^{37}$.

Precisamente por esto, es pertinente preguntarse por la posibilidad de pensar las identidades sexuales y de género de forma distinta a como se hace hoy en día. Incluso, es preciso ver si no hay ya otras formas de aproximación a la identidad de género y de sexo que pongan en entredicho todo este entramado teórico, abriéndonos otras posibilidades para el pensamiento y la vida democrática.

\section{DEL SEXO AL GÉNERO Y VICEVERSA}

Para seguir ahondando en esta cuestión es fundamental analizar la singular concepción de la identidad sexual y de género que la teoría de los "dos sexos inconmensurables", de origen dialéctico-romántico, suscita y promueve ${ }^{38}$.

La manera tradicional de hacer dicha incursión es recurriendo al vocablo patriarcado, pero consideramos que tal denominación, así como parte de su definición, no recoge bien la complejidad del asunto que se debe tratar. Otras veces, la forma de denominación ha sido la expresión "sistema sexo/género" que puso Gayle Rubin en circulación a mediados de los setenta, la cual ha sido reformulada años más tarde - precisamente, entre otras autoras feministas, por la propia Rubin $^{39}$ - . No obstante, no es este el momento de entrar en estas disquisiciones y no porque no tengan interés ${ }^{40}$. En nuestro caso usaremos, indistintamente, las expresiones "orden normativizado sexual y de género", "sistema de sexo/géne-

${ }^{37}$ Que hay hombres y mujeres es algo incuestionable. Esto ha sido así a lo largo de la historia humana conocida. Y lo ha sido así también tanto en la época donde predominaba la teoría de un único sexo, como en la de los dos sexos. Por tanto, eso no es lo que está en discusión, sino las justificaciones y explicaciones teóricas que definen dichas categorías.

${ }^{38}$ Para un recorrido por la teoría dialéctica y su relación con las concepciones predominantes sobre el género: Fernando FernÁndez-Llebrez, "Pensamiento retórico y masculinidades: de la dicotomía al continuum": Utopía y Praxis Latinoamericana, vol. 13, n. 43 (2008), pp. 85-102. Que esta identidad nazca en el mundo moderno no significa que sea representativa de toda la modernidad. En este sentido, como en tantos otros, es preciso hablar de modernidades, en plural.

${ }^{39}$ Gayle Rubin, "Reflexionando sobre el sexo: notas para una teoría radical de la sexualidad", en Carol VANCE (comp.), Placer y peligro, Editorial Revolución, Madrid, 1989, pp. 113-190.

${ }^{40}$ Para una genealogía del género que se adentra en estos debates, puede verse: Elena CASADo, "La emergencia del género y su resignificación en tiempos de lo post": Foro Interno. Anuario de Teoría Política, vol. 3 (2003), pp. 41-65. 
ro" o la de "ordenamiento sexista", aun reconociendo que dichas expresiones tienen sus problemas analíticos, pero lo intentaremos resolver no tanto en el terreno nominal (qué expresión o palabra usar), sino en el conceptual (a qué nos referimos en concreto). En este sentido, los rasgos que podemos destacar son los siguientes.

El primero se refiere a la idea, según la cual, la definición del sexo actúa como realidad verdadera ya existente sobre la que se construyen los géneros. La identidad sexual es algo natural que da consistencia objetiva y científica a la "teoría de los dos sexos", de tal modo que son la biología y la medicina las que actúan como campos de reflexión a la hora de definir al sexo y de señalar cuántos hay. Esta concepción supone una fundamentación naturalizada de la creencia de que hay dos sexos, y solo dos, no existiendo otras posibilidades.

El segundo rasgo remite a que dicha definición del sexo es, además, de carácter bipolar, es decir, binarista. A un lado está lo masculino (la identidad masculina, el hombre) y al otro lo femenino (la identidad femenina, la mujer) configurando dos polos diferenciados entre sí y quedando en medio una sima enorme que los separa. Este binarismo se caracteriza por su dimensión dicotómica de tal modo que si se es una cosa (si se es hombre) no se puede ser la otra (ser mujer). Esta concepción se desarrolla creando categorías estándar que actúan a modo de estereotipos ${ }^{41}$ que califican y clasifican a la identidad masculina y a la femenina.

El tercer rasgo implica que dicha estereotipación no supone que no se den relaciones entre ambas categorías (sexo y género), ni entre ambos grupos (los hombres y las mujeres). La relación que se da entre hombres y mujeres es asimétrica, lo que se reflejaba en la desigual relación de poder que hay, y sigue habiendo, entre ambos. Pero también es de complementariedad, percibiéndose ambas identidades como si una completara a la otra. Algo que se manifiesta en la cuestión sexual (la heterosexualidad "obligatoria" o "generalizada" dentro de la tradicional idea de la "media naranja"), pero también en ciertos rasgos culturales (ternura/ firmeza; débil/fuerte; etc.).

Por su parte, la relación que hay entre lo sexual y lo genérico es una muy específica y de carácter mecanicista. Una vez identificado qué es lo sexual (que es objetivo, dado, natural) se le proyectan, de manera automática, los atributos a los géneros correspondientes (hetero, viril, reproductor, etc.). El resultado de esta forma de relación es que hay dos géneros (culturales), precisamente, porque

${ }^{41}$ George L. Mosse, La imagen del hombre. La creación de la moderna masculinidad, Talasa, Madrid, 2000, p. 9. 
anteriormente ha habido dos sexos (naturales), configurándose la pirámide sexual de la que, tan lúcidamente, nos habló Rubin ${ }^{42}$.

Para este razonar, que no para Rubin, la desigualdad se establece solo en el terreno de los géneros, el cual es cultural (y, por ende, modificable), viéndose el sexo como una sustancia "meramente" natural; sustancia que, aunque esté sosteniendo dicha discriminación, es indiscutible, invariable e inamovible, precisamente, por ser natural.

Como cuarto rasgo destaca que, tanto la identidad sexual como la de género, son cuestiones trascendentales para las personas, cobrando una importancia muy relevante en nuestras vidas. Relevancia que hará que la sexualidad adquiera una dimensión pública, definiéndose desde un punto de vista moral y convirtiéndose en objeto de control. Es así como aparecerá lo que se denomina la "buena" y la "mala" sexualidad, que conllevará un proceso de normativización y reglamentación respecto al sexo y el género muy importante. Entre otros autores, esto ha sido estudiado por Michel Foucault (1926-1984) para la Inglaterra victoriana y por George Mosse para el caso alemán ${ }^{43}$. Ambos autores muestran como algo que no tenía relevancia pública termina formando parte de los elementos que definen nuestra vida en común y lo hace, además, de una manera destacada.

Como quinto rasgo destaca la forma que tiene este razonamiento binario de definir a los seres humanos en general. Cuanto menos es singular porque es una definición portadora de una específica identidad sexual y genérica (la masculina) que, además, actúa como referente para el conjunto de la normatividad sexual y social ${ }^{44}$. Tal y como plantea Benhabib, esta concepción solo puede ser abordada satisfactoriamente haciendo de la definición de "lo masculino" algo con "doble significado": remitiendo, al mismo tiempo, a lo específico (los varones) y a lo general (hombre como ser humano). Un "doble significado" que tendrá como consecuencia que lo general se identifique con lo masculino y viceversa ${ }^{45}$. No obstante, hay veces que la consideración de la identidad sexual como algo trascendental(ísimo) toma otro camino, aquel que postula una diferenciación radical

${ }^{42}$ RUBIN, "Reflexionando sobre el sexo", pp. 140ss. No obstante, también pudiera ser al contrario, tal y como plantea Christine Delphy, de tal modo que lo primero haya sido el género y "luego" el sexo. Para una mayor profundización en esta polémica, véase Christine DeLPHY, "Rethinking sex and gender": Women's Studies Int. Forum, vol. 16, n. ${ }^{\circ} 1$ (1993), pp. 1-9.

${ }^{43}$ Foucault, Historia de la sexualidad, passim y Mosse, La imagen del hombre, passim.

${ }^{44}$ Mosse, La imagen del hombre, pp. 23-49.

${ }^{45}$ Seyla BENHABIB, "El otro generalizado y el otro concreto: la controversia Kohlberg-Gilligan y la teoría feminista", en Seyla BENHABIB y Drucilla CoRnell, Teoría feminista y teoría crítica, Alfons el Magnánim, Valencia, 1990, pp. 135ss. 
entre géneros y sexos, siendo imposible imaginar ni hablar de ningún tipo de "humanización general"46.

Pero ya se diga que es imposible generalización alguna o se hable de una generalización en la que la parte (masculina) sustituye al todo, la cuestión es que, para esta concepción, la identidad es una y solo una: la identidad es idéntica. De esta forma si hay (una) identidad, no hay diferencia (interna) posible y si hay diferencia (interna), no hay identidad posible. De ahí, que quien cruce las fronteras establecidas sea visto como un ser o bien sin identidad y, por lo tanto, perdido y en constante crisis, o bien un ser directamente "trastornado". Pero sea como fuere, lo "normal" no pasa por dicho cruce, sino por el camino contrario.

Pues bien, si queremos decir, y saber, algo más sobre ese supuesto cruce imposible, es pertinente abordar lo que dicen y hacen los y las transexuales en relación a la identidad sexual y de género, ya que ellos y ellas son un ejemplo real de dicho cruce.

\section{TRANSEXUalidades E IDENTIDADES DE GÉNERO Y SEXUAL}

Como es bien sabido, y desde un punto de vista general, una persona transexual es aquella en la que su identidad de género y sexual psíquica no se corresponde con su identidad morfológica (física). Es decir, que teniendo un cuerpo de hombre o de mujer, ella o él, se siente lo "contrario" a su aspecto físico. Hasta hace muy poco tiempo esta situación fue considerada como un "trastorno psíquico", llevando aparejadas toda una serie de tratamientos médicos de carácter psiquiátrico nada despreciables y muy dañinos para dichas personas ${ }^{47}$. Eran tratados y tratadas, y todavía hoy en cierta medida y en ciertos lugares lo son, como una "especie de alienígenas": como seres amorfos y depravados. Hoy, y gracias a las reivindicaciones de grupos de transexuales y de algunos grupos feministas ${ }^{48}$, esta concepción está cambiando a mejor aunque todavía no lo suficiente.

Lo que sí que es un elemento común, por lo menos dentro de la mayoría de especialistas así como en el conjunto de los propios grupos de transexuales, es la

${ }^{46}$ Un ejemplo de este planteamiento lo tenemos en Luce IrIGARAY, Ese sexo que no es uno, Akal, Madrid, 2009, passim.

${ }^{47}$ José Antonio Nieto, "Transgénero/Transexualidad: de la crisis a la reafirmación del deseo", en José Antonio Nieto (comp.), Transexualidad, transgenerismo y cultura. Antropología, identidad y género, Talasa, Madrid, 1998, pp. 11-37.

${ }^{48}$ Para este menester, ver Cristina GaraizaBAL, "La transgresión del género. Transexualidades: un reto apasionante", en NiETo, Transexualidad, transgenerismo y cultura, pp. 39-62. 
aceptación de que, en este conflicto de identidades, es el elemento subjetivo el que más pesa. Es decir, que no se trata de ningún trastorno psíquico de carácter clínico y que, en todo caso, debe ser el cuerpo, la morfología, la que se adapte a dicha realidad, para lo cual es necesario que haya recursos financieros de carácter público que atiendan dicha demanda.

Esta consideración ya supone abrir una vía de quiebra para con el modelo binarista, puesto que la identidad puede desgajarse de la morfología, de tal modo que es la subjetividad la que la termina definiendo, lo que deja maltrecha la idea naturalizada y corpórea que identifica a la identidad sexual, a qué es un sexo, con su apariencia externa. Toda una ruptura que conlleva un primer paso en el proceso de distanciamiento respecto de la concepción identitaria binaria ${ }^{49}$.

No obstante, dentro de los y las transexuales se pueden apreciar dos maneras de abordar esta crisis de identidad. Los hay, y las hay, que no soportan vivir dentro de un cuerpo que no se corresponde con su identidad subjetiva y desean operarse con el propósito de adecuar su morfología a su subjetividad. Pero también los hay y las hay que, si bien reconocen esa disparidad entre la morfología y la subjetividad, se sienten bien con dicha "dislocación", llegando a convivir con un cuerpo que, morfológicamente, es "mitad masculino, mitad femenino" (es decir, v. gr.: órgano genital masculino y pechos), desestructurando, así, la distinción bipolar entre hombre y mujer.

Desde nuestro punto de vista, tanto quienes se quieren operar como los que no, forman parte del colectivo de transexuales aunque, a veces, a unos y unas (a quienes sí quieren operarse) se le denomina como transexuales y a los otros u otras (a quienes no desean operarse) se les denomina como transgenéricos. Si bien tanto una como otra experiencia conforman la realidad transexual, en este artículo nos vamos a centrar en aquellos y aquellas que, por motivos variados, se sienten cómodos en esta hibridación morfológica y psíquica en la que viven y que, siendo diferentes a los drag queen o los travestis, tienen una cercanía con estos a la hora de abordar la caracterización de la identidad masculina y femenina. Y para que no haya confusión en el lenguaje, y aunque nos parece más adecuada la expresión de transexuales (en plural), tomaremos la expresión transgenéricos para denominar ese colectivo específico.

En este sentido, la pregunta teórica que nos tenemos que hacer es la siguiente: ¿qué plantea en concreto el transgenerismo en relación a la identidad sexual

${ }^{49}$ José Antonio NiETo, Transexualidad, intersexualidad y dualidad de género, Ediciones Bellaterra, Barcelona, 2008, passim; y Patricia Soley-BeltrÁn, Transexualidad y la matriz heterosexual: un estudio crítico de Judith Butler, Ediciones Bellatera, Barcelona, 2009, passim. 
y de género? De manera resumida, podríamos decir que los y las transgenéricas construyen una identidad de género que, cuanto más diferente es en el sexo (cuando mezclan en un solo cuerpo, por ejemplo, órganos genitales de un "sexo" con morfologías del otro "sexo") menos distinción y desconsideración hay para con el otro género, al asumir, en una misma corporalidad, rasgos culturales masculinos y femeninos. Al mezclar sus diferentes morfologías sexuales, también hibridan en cuanto a los géneros, siendo algo que afecta, además, tanto a su presente, como a su pasado y a su futuro.

Por tanto, a mayor diferenciación sexual, es decir, a mayor distancia en relación a los dos sexos conocidos tradicionalmente, no hay más desconsideración hacia el otro (género y sexo) sino, por el contrario, mayor aproximación hacia el otro (género y sexo).

Si analizamos atentamente lo que se acaba de decir comprobamos cómo esta redefinición supone un claro cuestionamiento de aquello que caracterizaba a la identidad binaria característica de las políticas de identidad culturalistas. Para esta concepción lo que define la identidad es que esta une y al hacerlo marca distancias con lo diferente, de tal modo que a mayor diferenciación y afirmación propia, mayor distinción respecto del otro. De ahí que dichas políticas de identidad marquen muy claramente las diferencias entre los distintos grupos (mujer, lesbiana, gay, etc.).

Sin embargo, en el caso de los y las trangenéricas la cosa no es así. Es verdad que su identidad marca distancias en cuanto al cuerpo (morfológico), pero no lo es que dicha diferenciación conlleve una mayor distinción respecto del otro (ya sea hombre o mujer), sino más bien al contrario: una menor distinción que nos expresa una relación de continuidad entre ambos sexos. Esta concepción de la identidad es minoritaria y particular tanto en cuanto caracteriza una forma de entender la transexualidad. Pero también puede tener una dimensión más amplia al repercutir sobre la definición general de la identidad sexual y de género imperante hoy en día ${ }^{50}$.

Entre las características definitorias del denominado "sistema sexo/género", destaca su concepción binarista y dogmática a la hora de apelar a los géneros y los sexos. Es cierto que si tomamos la expresión más dura o conservadora de este planteamiento su rigidez es tal que no cabe ni la posibilidad de aceptar la diversidad de géneros, de sexos y de opciones sexuales. Pero si nos aproximamos a

\footnotetext{
${ }^{50}$ Para la relación entre las identidades mayoritarias y minoritarias véase Eve K. SEDGWICK, Epistemología del armario, Ediciones de la Tempestad, Barcelona, 1998, pp. 11-90.
} 
versiones menos estrictas o más progresistas, nos encontramos con que no es incompatible la aceptación de esta mirada binarista con el reconocimiento e igual consideración de, por ejemplo, diferentes opciones sexuales.

Es decir, se puede asumir esta aproximación teórica y, a la vez, reconocer la legitimidad de cuantas opciones sexuales se quiera (gay, lesbianismo, heterosexualidad, etc.). Es más, desde este planteamiento binarista también es factible reconocer a la transexualidad que tiene como fin la operación, más allá de si se está de acuerdo o no con financiar públicamente dichas operaciones. Esto es así porque al realizarse dicha operación ${ }^{51}$ lo que se está produciendo es una readecuación, en términos de identidad, a uno de los dos sexos establecidos, lo cual no vulnera en absoluto el binarismo existente, sino que más bien lo reafirma ${ }^{52}$.

Sin embargo, lo que resulta complicado aceptar para el planteamiento binarista es una realidad que cuestione sustantivamente su background en relación a la identidad de género y de sexo. Y eso es lo que precisamente ocurre cuando pensamos en el transgenerismo, es decir, en la transexualidad que no tiene como meta la operación. ¿Y por qué?

El background que define al conjunto de la teoría binarista, en cuanto a su definición del sexo, se caracteriza por desplegar una concepción dicotómica según la cual hay dos, y nada más que dos, sexos de carácter opositivo en los que tienen que encajar y entrar todas las identidades sexuales existentes. Un planteamiento similar ocurre a la hora de hablar del género cuando se señala que hay dos y solo dos géneros y que estos también son de carácter opuesto. Ejemplo de ello son afirmaciones tan comunes como que "los hombres y las mujeres conformamos dos universos distintos y metafísicamente diferentes".

Es así como dicha concepción tiene capacidad para aceptar una variedad de opciones sexuales, lo cual no contradice sus supuestos teóricos, pero, del mismo modo, "le cuesta aceptar" una realidad que vaya más allá de dicha dicotomía opositiva (sea esta heterosexual versus homosexual, femenino versus masculino...), tal y como ocurre con las y los transgenéricos. De ahí que este planteamiento les termine dejando fuera al no encajar este en dicha dualización. Una exclusión que hace que los y las trangenéricas acaben siendo o bien la más pura nada (representando la quintaesencia de la inexistencia humana), o bien formen parte de algún programa clínico sobre trastornos de personalidad.

Lo que los y las transgenéricas plantean es una hibridación ${ }^{53}$ que mezcla

\footnotetext{
${ }^{51}$ Acto legítimo que, desde nuestro punto de vista, debe estar financiado públicamente.

${ }^{52}$ Esto no quiere decir que todos los y las transexuales que se operen acepten dicha lógica binaria, sino solo que tal proceso se puede desarrollar coherentemente dentro de dicho planteamiento, lo que no es lo mismo.
} 
partes de la masculinidad y partes de la feminidad, produciendo una dislocación identitaria que supone un cuestionamiento de la masculinidad y la feminidad como dos todos ya prefijados. Este cruce sexual y de géneros de los y las transgenéricas significa una redefinición de la relación entre los géneros y los sexos al establecer un continuum entre ambos, lo que rompe con la concepción binaria establecida. Un continuum que no conlleva desconsiderar ni al hombre ni a la mujer, sino, por el contrario, un proceso de hibridación en cuanto a los géneros y sexos. Una hibridación radical que, parafraseando a Benhabib, supone entender las identidades de género y sexual como realidades polivocales, descentradas y fracturadas ${ }^{54}$; una hibridación que les ubica fuera de la escala social establecida al considerarse dicho mestizaje como una impostura moral y social ${ }^{55}$. Tan es así que, desde el punto de vista sexual, son considerados y consideradas sin "sexo oficial".

Transgredir los géneros supone cuestionar los roles establecidos, lo cual no encaja bien con el binarismo de género. Pero dicha desubicación no tendría que ser vista así por los propios grupos de afirmación sexual ni por los de identidad de género. En ningún caso, el o la transgenérica, en lo referido al género, supone algo muy diferente de lo que gays, lesbianas, mujeres del movimiento feminista y personas vinculadas a esta tradición puedan plantear. Sí es más visible, más personal, más llamativo y más extremo, si se quiere, pero no tiene por qué ser algo ajeno a dicha realidad.

Por el contrario, su hibridismo sexual sí que desplaza a los y las transgenéricas fuera de los límites en los que se mueven tanto el binarismo social imperante, como la mayor parte de los propios grupos de afirmación sexual. Para el planteamiento binario, y para ciertos grupos de afirmación, se será gay, lesbiana, heterosexual u otra cuestión, pero se es, a la vez, o mujer u hombre y con una clara morfología. De ahí que el transgenerismo, al romper dicho planteamiento dicotómico, no solo cuestiona el background socialmente existente, sino también el que sostiene a ciertos de estos grupos.

Es cierto que la hibridez morfológica y subjetiva de los y las transgenéros les diferencia de manera profunda. Pero, también, que es una diferenciación que

${ }_{53}^{53}$ Seyla BenHABIB, Las reivindicaciones de la cultura. Igualdad y diversidad en la era global, Katz, Buenos Aires, 2006, p. 61. También puede acudirse a Donna HaraWAY, Ciencia, cyborg y mujeres, Cátedra, Feminismos, Madrid, 1995, passim.

${ }^{54}$ BenHABIB, Las reivindicaciones de la cultura, p. 61.

${ }^{55}$ RuBin, "Reflexionando sobre el sexo", pp. 159ss. 
no crea una barrera más. Más bien es al contrario: su diferencia sexual lo que hace es aproximar géneros y sexos. Y al hacer esto nos señalan la pertinencia de diferenciar tres dimensiones que, para la teoría de los "dos sexos inconmensurables" y su identidad binaria se consideraban unidas: el sexo anatómico, por un lado, la identidad de género (cómo uno o una se siente), por otro, y, por último, la actuación del género (los rasgos atribuidos a cada género) ${ }^{56}$. La ruptura de la unidad entre el sexo y el género implica reconocer un dinamismo identitario a la hora de definir los géneros y los sexos que, debido a su capacidad de desplazamiento, pone en solfa la propia concepción binarista. Un dinamismo que da sentido a lo que, siguiendo a Benhabib, podríamos denominar como "construcciones dinámicas de la identidad" ${ }^{57}$ y que va a tener repercusión no solo sobre los y las transgéneros, sino también sobre la concepción binaria que caracteriza a las identidades masculinas y femeninas imperantes hoy en día. ¿Y en qué sentido es así?

En primer lugar, ya no apelaríamos a una supuesta verdadera identidad de género y sexual de carácter esencialista y binarista. Más bien, hablaríamos de una identidad construida social y personalmente que, por ser tal, es reversible y, por ende, no necesariamente dicotómica. Un constructivismo fundacional que no defiende que seamos una página en blanco, sino una interacción entre lo biológico, lo social y lo psicológico donde la última palabra todavía no está escrita, teniendo capacidad para actuar sobre dicha compleja realidad ${ }^{58}$.

En segundo lugar, tampoco hablaríamos de los hombres y de las mujeres como dos esencias, como dos sustancias, radicalmente distintas que contienen dos universos ya predefinidos. Por el contrario, hablaríamos de los hombres y las mujeres como categorías sociales o políticas, interconectados entre sí, a través de un continuum entre dos polos que posibilita la transferibilidad, compleja y múltiple, de los diferentes atributos de género y sexo, haciendo de la identidad una realidad diversa y mutable ${ }^{59}$. Una transferibilidad en donde la hibridación de sexos y géneros es una posibilidad más. Pero, ahora, es una posibilidad real integrada dentro de los marcos de género y sexuales y no una especie de anomalía, como ocurre en la concepción binarista. Unas identidades sexuales y de género

${ }^{56}$ BUTLER, Gender trouble, p. 174.

${ }^{57}$ BenHABIB, Las reivindicaciones de la cultura, p. 117.

${ }^{58}$ Fernando FernÁndEZ-LLEBREZ, “¿'Hombres de verdad’? Esterotipo masculino, relaciones entre los géneros y ciudadanía”: Foro Interno. Anuario de Teoría Política, vol. 4 (2004), p. 19; y Jeffrey WeEks, “¿Héroes caídos? Todo sobre los hombres”, en AA.VV., Héroes caídos. Masculinidad y representación, Generalitat Valenciana, Valencia, 2001, pp. 151ss.

${ }^{59}$ WEEKS, “¿Héroes caídos?”, p. 179. Para la relación entre identidades cambiantes y la ciudadanía democrática, véase Sheldon S. Wolin, Democracia S.A. La democracia dirigida y el fantasma del totalitarismo invertido, Katz, Buenos Aires, 2008, pp. 402ss. 
que al estar insertadas en dicho continuum, y no en su dicotomía, pueden despedazar el binarismo sexual y de género imperante, afectando, así, tanto a la identidad masculina como a la femenina.

Esto no significa que no haya diferencias sociales y políticas, que - como las semejanzas - las hay ${ }^{60}$. Estas diferencias quedan relacionadas con la desigual relación de poder existente; con los procesos de socialización y la plural interiorización de las experiencias (personales y culturales); con la estereotipación, trascendentalidad y fijación de las identidades ya establecidas; y con aspectos biológicos y morfológicos. Pero no ya con una supuesta ontología de género ni sexual que remita a dos entes distintos (ya sea apelando a "razones" biológicas o culturales).

Por todo esto es por lo que hombres y mujeres no transgenéricas (drag queen, travestis, hombres y mujeres en general) pueden identificarse y desarrollar dicha transgresión genérica. Y lo pueden hacer sin tener que dejar de sentir lo que uno o una quiera sentir, sino redefiniendo el concepto de identidad de género y de sexo imperante. No obstante, esto no es ni sencillo ni baladí, siendo preciso reconocer las dificultades que ello comporta ya que no hablamos de personas como páginas en blanco. Pero que este proceso sea complicado no significa que sea imposible, ni que no tengamos la capacidad para sentirnos libremente.

Lo que si supone es un reto para que hombres y mujeres podamos construir identidades de género y sexuales no dicotómicas ni estereotipadas, siendo conscientes de que la diferenciación no es sinónimo de negación, sino que puede llevar aparejada una reconsideración transversal de los propios géneros y sexos. Como dice Benhabib, hablamos de una reconsideración que sea capaz de "captar las transiciones fluidas que pueden producirse en el status de los grupos, a medida que estos se desplazan de una categoría a otra" ${ }^{1}$. Una forma de definir las identidades de género y de sexo como posibilidades modificables que no remiten a una esencia inamovible y que rompe con las politicas de enclave cultural al permitir que "el disenso, el debate, la controversia y el cuestionamiento ocupen el centro" 62 de sus prácticas.

${ }^{60}$ Diferencias de género que al cruzarse con otras variables como la raza, etnia, clase social, etc., dibujan un panorama profundamente plural que es preciso atender. Para esta cuestión ver: Nancy FraSER, Escalas de justicia, Herder, Barcelona, 2008, pp. 31 y ss.

${ }^{61}$ BenHABIB, Las reivindicaciones de la cultura, p. 117.

${ }^{62}$ Ibid., p, 129. 


\section{INCLUSIÓN, DEMOCRACIA E IDENTIDAD}

Reconocer que las identidades de género se caracterizan por su fluidez supone replantearnos no solo nuestra privacidad sino también nuestros espacios públi$\cos ^{63}$. Supone relacionar la democratización pública con la privada ya que la democratización de nuestras identidades colectivas, relativas al género y al sexo, requiere desafiar la lógica oculta de muchas de estas categorías. De ahí que hayamos dicho que las identidades de género y sexual sean categorías políticas. No porque contengan un cariz ideológico - que no lo tienen-, sino porque su sentido lo adquieren por su incardinación en la vida pública y, en concreto, en una vida pública democrática.

En este sentido se ha expresado Benhabib cuando manifiesta que el objetivo de esta concepción teórica "sería llevar a la sociedad democrática hacia un modelo de vida pública en la que los relatos de autoidentificación serían más determinantes del propio status en la vida pública que los indicadores y los índices que otros nos imponen" ${ }^{64}$. Incorporar esta concepción identitaria sobre los géneros y los sexos al pensamiento y la práctica democrática supone abrir una perspectiva de inclusión para los y las transgenéricas, pero también para aquellas mujeres y hombres que no se sientan reconocidos, ni reconocidas, dentro de los estereotipos dicotómicos masculinos y femeninos imperantes hoy en día. Un planteamiento que, como dijimos, nos permite reconocer más posibilidades para nuestra vida con géneros, desplegando una manera de vivir más igualitaria, libre y digna. Objetivos estos que forman, o deben formar, parte del legado básico de cualquier teoría democrática de carácter moderno.

En la identidad binaria y dicotómica solo caben quienes se ubiquen en cada uno de los dos polos establecidos, abriéndose una sima tremenda para quienes quedan en el medio. Una mirada que solo permite el desarrollo de identidades dogmáticas y rígidas en la que se da una relación de (mono)causalidad entre sexo y género. Estas identidades dicotómicas se ven como las verdaderamente legítimas y son las que tendrán, y tienen, consideración y reconocimiento tanto público como privado. Es una concepción cerrada de la identidad que termina produciendo una menor pluralidad.

Sin embargo, en la perspectiva de la identidad como continuum caben tanto los polos como los puntos intermedios que delinean su interconexión, lo que

\footnotetext{
${ }^{63}$ BenHabiB, El Ser y el Otro en la ética contemporánea, pp. 17 y ss.

${ }^{64}$ BENHABIB, Las reivindicaciones de la cultura, p. 143.
} 
genera una profunda y compleja desestructuración de la (establecida) relación entre sexo y género. De este modo, la sima existente se "rellena" cubriéndose de posibilidades, pudiéndose dar identidades tanto claras como ambiguas al desarrollar un planteamiento en el que la fluidez siempre está presente. Así, su capacidad de reconocimiento es mayor por lo que se ensancha nuestra pluralidad. Es decir, es una concepción abierta de la identidad que termina agrandando la democracia, precisamente, porque permite incorporar nuevos campos de posibilidades para nuestra vida con géneros.

Pero esta ruptura con el binarismo establecido también supone un reconocimiento de la "autodesignación identitaria" frente a la "heterodesignación normalizadora" ${ }^{65}$, lo que facilita un planteamiento crítico contra la normativización sexual y de género. Un pensamiento crítico que nos hace más libres y nos permite un mejor y mayor gobierno del ciudadano democrático ${ }^{66}$.

No obstante, esto no significa que se hayan resuelto las cuestiones de la identidad de una vez para siempre. La riqueza de la identidad como continuum está, precisamente, en la posibilidad de mantener vivas las contradicciones mostrando su carácter fluido, dinámico e híbrido. De ahí que no sea adecuado entenderla como la nueva y definitiva solución ante los problemas de la identidad en nuestras democracias. Es más, para que los propósitos democráticos sean más fructíferos muchas veces el continuum identitario requerirá un diálogo complejo ${ }^{67}$ con ciertas políticas de identidad ${ }^{68}$ y sus respectivos derechos afirmativos. Un proceso de diálogo que, siguiendo a Benhabib, puede denominarse como de "reconstrucción reflexiva de las identidades" ${ }^{69}$ y que brinda una alternativa más democrática que la política binarista imperante. Una definición de la identidad que, aceptando su dimensión contingente, pretende desplegar una mirada lo más inclusiva, libre y sana posible de nuestras vidas con género.

Si bien estos son los objetivos hacia los que se encamina dicha concepción teórica, no está de más preguntarnos por cómo podríamos acercarnos a ellos.

${ }^{65}$ GaraizaBal, "La transgresión del género", pp. 59 y ss.

${ }^{66}$ Para el gobierno del ciudadano, véase RoIz, La recuperación del buen juicio, pp. 321ss.; Javier RoIz, Sociedad vigilante y mundo judio en la concepción del Estado, Editorial Complutense, Madrid, 2008, pp. 85ss.; y Alonso, Retórica, democracia y crisis, pp. 218ss. Para la "democratización del self", puede acudirse a Wolin, Democracia S.A., pp. 400-401.

${ }^{67}$ BenHABIB, Las reivindicaciones de la cultura, p. 129.

${ }^{68}$ Evidentemente, unas políticas de identidad que ya no pueden ser definidas de manera culturalista, sino de forma política o cívica.

${ }^{69}$ Ibidem. 
Para ello, una buena pista es conocer lo que han hecho y dicho quienes han discutido, criticado y cuestionado, desde hace ya bastante tiempo, los estereotipos de géneros dominantes en nuestras sociedades occidentales, por si nos sirviera de algo. Esta será nuestra última parada.

\section{FeMinismos, CAMbios CULTURALES y MALESTARES DE GÉNERo}

Son los grupos sociales que no han formado parte de los estereotipos de género ${ }^{70}$ (mujeres, homosexuales, lesbianas...) los que, junto a algunos de los cambios sociales y culturales acaecidos, han protagonizado las sucesivas crisis que han sufrido los estereotipos de género a lo largo de su historia, pese a su persistencia.

Si nos centramos en la época contemporánea, y en concreto a partir del siglo diecinueve, nos encontramos con que fueron movimientos sociales y políticos como el pro-abolicionista o antiesclavista (que igualaba a negros con blancosa lo no occidental con lo occidental-), o ciertos (y desiguales) procesos de integración social (judíos, gitanos, etc.), o las críticas al antisemitismo quienes denunciaron a los estereotipos de género por su carácter excluyente. Ni que decir tiene que el movimiento sufragista de las mujeres (que no por casualidad, en un principio, iba de la mano del pro-abolicionista ${ }^{71}$ supuso un duro golpe al estereotipo femenino, y por extensión al masculino, al cuestionar las diferencias en cuanto al derecho de voto, lo que implicaba sacar del espacio privado a las mujeres otorgándole un papel más activo, público y de igualdad que no quedaba recogido dentro del ideal masculino.

Pero no solo hubo críticas a tales estereotipos en estos grupos sociales. También ciertos procesos históricos y movimientos culturales ponían en solfa la quietud y serenidad de dichos estereotipos: la crisis espiritual sufrida tras la Primera Guerra Mundial, los tiempos convulsos del período de entreguerras, así como la crítica que conllevaban las vanguardias artísticas al ideal de belleza (cubismo, expresionismo, etc.) son algunos ejemplos que fueron erosionando los respectivos estereotipos de género.

No obstante, también hubo otros procesos sociales que afianzaron los estereotipos de género. Unos tuvieron una influencia indirecta como los brotes nacionalistas; el fascismo y el nazismo; la propia experiencia soviética; la propia guerra mundial, etc. Pero también están los que tuvieron una relación más directa

\footnotetext{
${ }^{70}$ FernÁndeZ-Llebrez, “ ¿'Hombres de verdad’?”, p. 23.

${ }^{71}$ SÁNCHEZ, "Genealogía de la vindicación”, pp. 35-43.
} 
sobre los estereotipos de género como la consolidación de la división del trabajo, la familia tradicional, el puritanismo, etc. Todos estos fueron, y algunos siguen siendo, factores que consolidaron los estereotipos masculinos y femeninos.

En tiempos más recientes, en particular desde los años sesenta en adelante, también estos estereotipos se han visto discutidos y problematizados. Lo que se conoce como la segunda ola del feminismo, aun con toda su pluralidad, lo que nos obliga a hablar de feminismos ${ }^{72}$, supuso un claro menoscabo de muchos de los elementos que definen al ideal masculino ${ }^{73}$ : la crítica a la separación público versus privado; la reconsideración y, a la vez, problematización de la ética del cuidado; el cuestionamiento de la heterosexualidad obligatoria y la legitimidad del lesbianismo; la crítica a la consideración de que las mujeres tienen una sexualidad pasiva; la liberación sexual y la ruptura con la idea de "nerviosismo"; la denuncia de la violencia de género; el reconocimiento de la pluralidad de mujeres y su crítica a los modelos y la normativización (y normalización); o el cuestionamiento de que existe una esencia femenina, son algunos ejemplos de planteamientos que socavan el estereotipo femenino $\mathrm{y}$, debido a su carácter relacional, también el masculino.

También los grupos gays ayudaron a este cometido rompiendo la identificación entre hombre y heterosexualidad, ampliando las formas de ser hombres, así como la exigencia de sus derechos. Los grupos de identidad de género (transexuales, transgenerismo, etc.) que discuten la naturalización de los sexos y los géneros, y ciertos grupos de hombres (los denominados como antisexistas o profeministas), que cuestionan los modelos de masculinidad imperantes y despliegan una actividad pública frente a la violencia de género, son otros ejemplos de críticas hacia el estereotipo masculino y, por contagio, del femenino.

Pero como ocurrió antaño, también hubo cambios, movimientos culturales más amplios, que trastocaron dichos estereotipos. Seguramente el movimiento juvenil de los años sesenta y setenta sea el caso más notorio; la contradictoria generación beat que no hacía gala de su hombría y apostaba por relaciones sexuales tanto con mujeres como con hombres; o la música popular, encabezada por grupos como The Beatles que cambiaron la estética, o los múltiples grupos de rock que pluralizaron mucho la realidad vital y personal; o grupos como los hippies, los punkies, etc. Incluso los cambios acaecidos en la publicidad son

${ }^{72}$ Celia Amorós y Ana de Miguel (eds.), Teoría feminista: de la ilustración a la globalización, vol. 3, De los debates sobre el género al multiculturalismo, Minerva, Madrid, 2005.

${ }^{73}$ No todo feminismo defiende lo que se dice a continuación, pero sí ciertas corrientes. En algunas de las temáticas señaladas sí hay más unidad. 
algunas muestras prácticas de esto. Ejemplos que ponían en cuestión los ideales masculinos y femeninos por su variada y múltiple forma de celebrar e incorporar el intrusismo en nuestras vidas. Un trastoque que, incluso, se llegó a ver, como no podía ser menos, como un momento de declive y pánico moral ${ }^{74}$.

Del mismo modo, la creencia de que vivimos un cambio de época que descoloca ciertas normatividades pone en solfa elementos característicos de los estereotipos; o el reconocimiento de las sociedades multiculturales, y más la interculturalidad, a partir del fenómeno migratorio en Europa, vuelve a traer fantasmas occidentales en donde siguen operando actitudes masculinas y femeninas estereotipadas.

No obstante, y como también ocurriera antes de la Segunda Guerra Mundial, había y hay factores que siguen apuntalando y afianzando los estereotipos de género. Las crisis económicas (que reafirma la división del trabajo); la reacción moral conservadora (de la que forman parte ciertos grupos de hombres que ven una pérdida de poder masculino y postulan la recuperación de la "perdida esencia masculina"); algunas facetas militarizantes de los propios años sesenta y setenta; la exclusión de los inmigrantes, identificados como "lo diferente"; la legitimación de los malos tratos y de la violencia a la hora de resolver conflictos interpersonales; la aceptación superficial del feminismo; las reticencias hacia los gays y las lesbianas; y otros tantos factores son la otra cara de la moneda. Por tanto, como se aprecia, los estereotipos de género no solo son normatividades cambiantes y sujetas a desgaste, sino que además forman parte de las sociedades, quedando insertas en los cambios y persistencias que también acontecen en ellas ${ }^{75}$.

Si bien todo este recorrido nos muestra una realidad diversa, también lo es que se pueden encontrar ciertos planteamientos comunes que atraviesan el conjunto, o la mayoría, de las críticas que se le han realizado a los estereotipos de género. De forma resumida, estos planteamientos comunes los podríamos agrupar en dos ideas motrices.

Por un lado, aquellas que supusieron, y suponen, una crítica a las relaciones de poder que vertebran las relaciones entre los géneros y las opciones sexuales. Un elemento que es central para cualquier teoría democrática, ya lo expresen los propios sujetos implicados o lo hagan otros por razones de solidaridad y justicia para con ellos y ellas.

\footnotetext{
${ }^{74}$ WeEKs, El malestar de la sexualidad, pp. 66-103.

${ }^{75}$ Para un planteamiento similar, ver FrASER, Escalas de justicia, pp. 31-64.
} 
Por otro lado, se encuentran aquellas ideas que plantean un profundo malestar con algunos de los elementos - los más característicos - que definen la identidad de un grupo. Por ejemplo, el cuestionamiento de la separación público/privado y la exigencia de que las mujeres sean también valoradas en el ámbito público, indica un claro malestar con lo designado como "ética del cuidado" 76 . Y no porque esta no contenga cosas positivas, que las tiene, sino porque también conlleva dolores, sinsabores nada despreciables para las mujeres que terminan generando daño. La exigencia a las mujeres de tener que estar siempre pendiente del "otro" no es una experiencia muy satisfactoria que se diga y que poca gente lo aguanta cómodamente. Este es un ejemplo de cómo situaciones que generan disgustos y dolores en las mujeres se convierten en malestares feministas hacia dicha normativización; malestares que conllevan una exigencia de autodesignación (autodeterminación) democrática, libre e igualitaria para las mujeres digna de encomio.

Por tanto, si analizamos esas experiencias — por lo menos algunas de ellas, las más profundas-, vemos que ha habido una crítica a las desiguales relaciones de poder, pero también un inconformismo ante ciertos sinsabores, ante ciertas "dolencias" sexistas que se transformaron en malestar(es) ante su propia situación y las causas que la generaron y generan. Una reconsideración crítica que nos muestra, además, que quienes se salen de dichas asignaciones y reglamentaciones terminan ganando más de lo que pierden, pese a lo duro que pueda ser el proceso $^{77}$.

Todos estos movimientos son ejemplos de cómo la historia cambia. En este caso, fueron y son cambios que abrieron brecha en pro de la igualdad y la libertad. De hecho, hoy vivimos un tiempo de crisis e impasse nada despreciable ${ }^{78}$. Pero también es verdad que la crisis de los estereotipos es más el resultado de una considerable erosión que el de un cuestionamiento por confrontación, de ahí

${ }^{76} \mathrm{La}$ ética del cuidado está relacionada con lo que se conoce como el yo-en-relación. Este lo puso en circulación Jean Baker MiLler (Psychoanalysis and Women, Brunner/Mazel, New York, 1973, passim) siendo preciso verlo en contraste con lo que se denomina como yo-en-los-logros. Para un desarrollo y actualización del significado del yo-en-relación véase Emilce Dio BLEICHMAR, La depresión en la mujer, Temas de Hoy, Madrid, 1991, pp. 85ss.

${ }^{77}$ No está de más reconocer que, en lo que acabamos de decir, una parte importante de las mujeres, y algunos hombres, llevan cierta ventaja a una parte considerable del conjunto de los hombres. Y, también, que no estaría mal que los hombres diéramos más pasos ya en esta dirección.

${ }^{78}$ Victor SeIDLER, Masculinidades. Culturas globales y vidas intimas, Montesinos, Barcelona, 2007, passim. 
su persistencia. Es decir, los estereotipos de género están en crisis (y más en las mujeres que en los hombres), pero aún siguen vivos ${ }^{79}$.

Tal y como hemos dicho, la erosión de los estereotipos ha estado protagonizada (aunque no en exclusividad) por aquellos grupos y personas que han quedado fuera de ellos. Pero los estereotipos de género no afectan solo a quienes fueron y son excluidos, sino que repercuten sobre el conjunto de las relaciones de género y sobre las formas de conceptualizar dichas identidades. De ahí que podamos afirmar que los problemas que contienen el desarrollo de los estereotipos de género, y su crítica, son cuestiones que nos afectan a todos y todas.

No solo el ideal masculino y femenino, en estado puro, son casi imposibles de alcanzar ${ }^{80}$, sino que hay razones para pensar que la mera existencia de los propios estereotipos de género también pueden generar dolor en (ciertos) hombres y mujeres, siendo posible hablar de la existencia de sinsabores y/o dolores de género. Esto es frecuentemente reconocido en lo que atañe a las mujeres, pero lo que se está planteando aquí es que también, aunque de forma distinta — pues está atravesada por una desigual relación entre los géneros-, estos dolores afectan, o pueden afectar, a los hombres.

En concreto, si miramos la realidad de los hombres comprobamos cómo los diferentes atributos que definen la masculinidad tradicional generan ciertos privilegios, pero también son fuente de dolor tanto propio como, sobre todo, ajeno. El control emocional, la obsesión por el éxito y los logros, la búsqueda del control y de la perfección, el deseo de omnipotencia y de autoexigencia, el poco cuidado hacia los demás y uno mismo (sobre todo desde el punto de vista emocional), el control a la hora de demostrar los afectos entre hombres (siempre que no se esté ebrio o en medio de un partido de fútbol), o la debilidad íntima de las amistades entre chicos son algunos sinsabores que, junto a cuestiones injustas, como la violencia contra las mujeres, el desigual reparto de las tareas domésticas o la ausencia de padres en la coeducación de los hijos e hijas (entre otras), diseñan un panorama poco alentador desde el punto de vista humano, tanto social como personal, para los hombres ${ }^{81}$.

${ }^{79}$ Cristina Garaizabal y Fernando FernándeZ-LLebrez, "Cambios y persistencias en la construcción de las identidades de género", en María Antonia CARO y Fernando FernándeZ-Llebrez (coords.), Buenos tratos: prevención de la violencia sexista, Talasa, Madrid, 2010, pp.133-197.

${ }^{80}$ FernándeZ-Llebrez, “ ¿'Hombres de verdad'?”, p. 37.

${ }^{81}$ Para la cuestión de la igualdad, véase Belén GonZÁLEz, "Ganando en igualdad, gana toda la sociedad. Algunos retos en un contexto de cambio social", en CARO y FERNÁNDEZ-LLEBREZ, Buenos tratos, pp. 103-132. Para el aspecto identitario: GARAIZABAL y FernánDEZ-LLEBrez, "Cambios y persistencias en la construcción de las identidades de género", pp. 133-197. 
Es cierto que estos posibles sinsabores pueden convertirse en un impulso para la reproducción individual y social, para la "aceptación, afirmación, celebración y propagación del poder individual y colectivo de los hombres" ${ }^{\prime 2}$. Pero, como señala Michael Kaufman, también "pueden servir de impulso para el cambio" $" 83$ aunque, para ello, es preciso convertir dicho dolor en malestar para con el estereotipo masculino y femenino, defendiendo relaciones igualitarias y de respeto entre los géneros y los sexos (igualdad para las mujeres y para las diferentes opciones sexuales), así como la libertad para configurar nuestras identidades sexuales y de género más allá de los estereotipos existentes.

$Y$ es aquí en donde la reflexión anterior sobre las identidades y su configuración cobra sentido, pues será partiendo de las identidades como un continuum como podremos romper las barreras que solidifican los estereotipos. De lo contrario, la sima y el vacío será la única alternativa ante la crisis de las identidades. Una sima que se preferirá no pisar, por el peligro que conlleva, con lo cual se terminarán cosificando, de nuevo, las identidades hoy problematizadas. De ahí la importancia democrática de incorporar dicha cuestión a la lucha contra la discriminación por razón de sexo.

Este cambio, cuanto menos, supone hacer justicia para con las mujeres y con aquellos que han sido estigmatizados (transexuales, gays, lesbianas, etc.). Una justicia reparadora que no puede ser obviada en las democracias del siglo veintiuno en las que vivimos y sobre la que la teoría política tiene mucho que decir. Es verdad que la teoría política en singular no existe, habiendo una pluralidad de formas de abordar estos cambios. Pero también lo es que no puede valer cualquier teoría política, porque podría significar una vuelta al mismo punto de partida. Ahondar en estos malestares supone desarrollar una forma distinta de pensarnos a nosotros mismos, de ahí que requiramos desplegar una mirada y una música capaz de acoger dichos cambios. Una música que, tal y como hemos visto, afecta a la cuestión de las identidades de género y sexual. Pero también a la propia idiosincrasia de la teoría política.

${ }^{82}$ Michael KAUFMAN: "La construcción del movimiento masculino dirigido a terminar con la violencia contra las mujeres". Conferencia impartida dentro del Programa para la igualdad de género en el sudeste de Asia, Canadá, s/f, copia mimeografiada, p. 6 (www.hombresigualdad.com/emak.construccionmm-kaufman). La versión original puede consultarse en: www.michaelkaufman.com.

${ }^{83}$ Ibidem. 
Y es aquí donde se torna oportuno tirar del hilo abandonado del humanismo cívico y de la retórica democrática ${ }^{84}$, pues ahí se encuentran muchas claves teóricas y prácticas para el gobierno de los ciudadanos que nos permiten transformar tales malestares en bienestares para hombres, mujeres, transexuales, etc. Y, para ello, es crucial retomar una concepción de la identidad donde los estereotipos de género y sexual no quepan (o encajen mal). Unas identidades que, aprendiendo de la experiencia transexual y transgenérica, se caractericen por desplegar un continuum entre hombres y mujeres que nos permita revertir y romper los dogmatismos de género existentes. Dogmatismos que de forma acuciante sufren los y las transexuales, y más aún los y las que no se quieren operar, pero también - aunque de manera diferente y desigual - aquellos hombres y mujeres que no quieren reproducir los estereotipos de género imperantes.

${ }^{84}$ Para esta cuestión: José Luis Ramírez, "El retorno de la retórica": Foro Interno. Anuario de Teoría Política, vol. 1 (2001), pp. 65-74; RoIz, La recuperación del buen juicio, passim; y Rorz, Sociedad vigilante y mundo judio en la concepción del Estado, passim. 